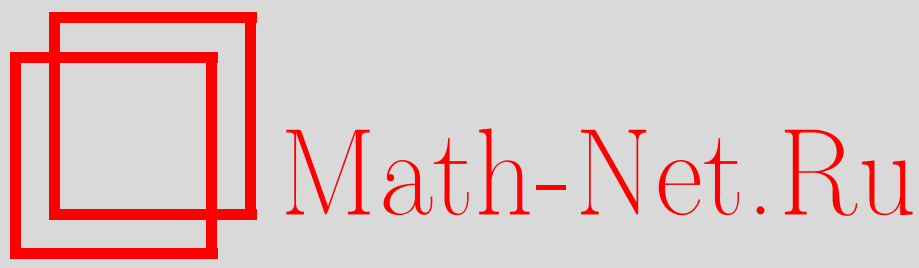

Ф. Х. Алтынбаев, Исследование резонансных движений астероидов группы Амура с внутренними планетами, Вестн. Сам. гос. техн. ун-та. Сер. Физ.-мат. науки, 2006, выпуск 43, 195-197

DOI: https://doi.org/10.14498/vsgtu478

Использование Общероссийского математического портала Math-Net.Ru подразумевает, что вы прочитали и согласны с пользовательским соглашением http: //www.mathnet.ru/rus/agreement

Параметры загрузки:

IP : 3.93.64.190

26 апреля 2023 г., 09:03:37

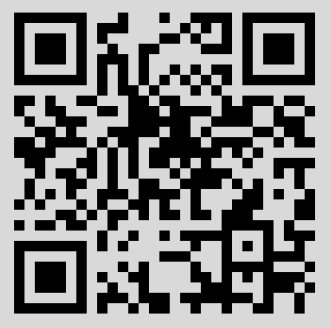




\section{ИССЛЕДОВАНИЕ РЕЗОНАНСНЫХ ДВИЖЕНИЙ АСТЕРОИДОВ ГРУППЫ АМУРА С ВНУТРЕННИМИ ПЛАНЕТАМИ}

Исследовано резонансное движение астероидов группь Амура с внутренними планетами. Показано, что из 1465 астероидов группь Амура 1215 движутся в резонансе с одной, двумя или тремя внутренними планетами. На интервале времени с 1800 по 2200 г2. исследована устойчивость резонансного движения астероидов группь Амура по отношению к внутренним планетам.

При решении задач, связанных с астероидной опасностью, особый интерес представляют астероиды групп Аполлона, Амура, Атона, так как орбиты астероидов этих групп касаются и даже проникают внутрь орбиты Земли и в случае тесных сближений с Землей могут представлять определенную угрозу столкновения. Особое место при исследовании занимают группы астероидов, имеющих характер движения, соизмеримый с движением больших планет. Для таких астероидов, благодаря соизмеримости, даже в случаях, когда их орбиты проходят близко к орбитам планет, всегда удается избежать тесных сближений с планетами, так как планета не оказывается на том участке орбиты, к которому приближается астероид.

Существование кратных соизмеримостей и резонансов у астероидов групп Аполлона, Амуpa, Атона по отношению к нескольким планетам были выявлены ранее рядом авторов [1-4]. В данной работе рассматривается резонансное движение астероидов группы Амура по отношению к большим планетам.

Суть проблемы заключается в том, что резонансный характер движения может наблююдаться не только при точной соизмеримости движения астероида с планетой. Отклонение от точной соизмеримости в любую сторону, при которой еще сохраняется резонансный характер движения, как раз и определяет ширину резонансной зоны. Если обозначить простые числа, входящие в резонансное соотношение, через $k_{1}$ и $k_{2}$, то ширина резонансной зоны окажется пропорциональной величине $1 /\left(k_{1}+k_{2}\right)$. Очевидно, что резонансная зона оказывается наиболее широкой при $k_{1}=k_{2}=1$.

В банке исходных данных элементов орбит астероидов DASTCOM ${ }^{1}$ (Database of ASTeroids and COMets) американской Лаборатории реактивного движения (JPL) по состоянию на 14 июня 2006 года содержалась информация о 1465 астероидах группы Амура.

На начальный момент времени 14 июня 2006 года из 1465 астероидов группы Амура вблизи резонанса по отношению к одной или нескольким планетам одновременно двигалось 1215 тел. При этом соизмеримости, близкие к резонансным с Венерой, проявлялись у 443 астероидов, с Землей - у 1077 и с Марсом - у 632 астероида. Здесь под понятием близкой соизмеримости понимается удовлетворение критерию резонансного характера движения астероида по отношению к отдельно взятой планете [2]:

$$
\left|k_{1} \cdot n_{1}-k_{2} \cdot n_{2}\right|=O(1) \sqrt{M},
$$

где $n_{1}$ и $n_{2}$ - среднесуточные движения астероида и планеты; $M$ - масса планеты; $k_{1}$ и $k_{2}$ — целые числа, соответствующие точной соизмеримости резонансного соотношения.

Из анализа начальных данных получено: $32 \%$ астероидов находится в резонансе только с одной из перечисленных выше планет, $33 \%$ находятся в резонансе по отношению к двум планетам и около $17 \%$ движется в резонансе сразу с тремя планетами - Венерой, Землей и Марсом.

Сведения о характере резонансных движений астероидов группы Амура к внутренним планетам на 14 июня 2006 года показаны в таблице, из которой видно,что наиболее широкие резонансные зоны с Венерой 2:1 и 3:1 у 15 и 77 астероидов соответственно. Широкие резонансы с Землей 2:1 и 3:1 наблюдаются у 169 и 309 астероидов. С Марсом в широких резонансах 1:1, 2:1 движется 88 и 172 астероида соответственно.

Для изучения устойчивости резонансного характера движения этих астероидов со временем были проведены исследования эволюции их орбит на интервале времени 400 лет - 200 лет в прямом и 200 лет в обратном направлениях от начального момента 14 июня 2006 года. Интегрирование уравнений движения астероидов проводилось численным методом Эверхарта

\footnotetext{
${ }^{1}$ ftp://ftp.lowell.edu/pub/elgb/astorb.htm
} 
с учетом возмущения 9 больших планет, Луны и Солнца в барицентрической системе координат [5-7]. Интегрирование велось с переменным шагом. Таким образом, были найдены резонансные соотношения для астероидов группы Амура по отношению к внутренним планетам на моменты времени 5 января 1800 года, 14 июня 2006 года и 8 января 2200 года. Сравнение резонансного характера движения на различные даты не выявило изменений в значениях $k_{1}$ и $k_{2}$ резонансных соотношений, а отклонение полученных резонансных отношений от точных соизмеримостей было не существенным.

Резонансные зоны астероидов группы Амура по отношению к внутренним планетам на 14 июня 2006 года

\begin{tabular}{|c|c|c|c|c|c|}
\hline \multicolumn{2}{|c|}{ Венера } & \multicolumn{2}{c|}{ Земля } & \multicolumn{2}{c|}{ Марс } \\
\hline$k_{1}: k_{2}$ & Кол-во & $k_{1}: k_{2}$ & Кол-во & $k_{1}: k_{2}$ & Кол-во \\
\hline $2: 1$ & 15 & $2: 1$ & 169 & $1: 1$ & 88 \\
\hline $3: 1$ & 77 & $3: 1$ & 309 & $2: 1$ & 172 \\
\hline $4: 1$ & 144 & $3: 2$ & 54 & $2: 3$ & 8 \\
\hline $5: 1$ & 184 & $4: 1$ & 255 & $3: 1$ & 4 \\
\hline $5: 2$ & 33 & $4: 3$ & 21 & $3: 2$ & 75 \\
\hline & & $5: 1$ & 92 & $3: 4$ & 12 \\
\hline & & $5: 2$ & 126 & $3: 5$ & 1 \\
\hline & & $5: 3$ & 42 & $4: 3$ & 62 \\
\hline & & $5: 4$ & 8 & $4: 5$ & 19 \\
\hline & & & & $5: 2$ & 55 \\
\hline & & & & $5: 3$ & 101 \\
\hline & & & & $5: 4$ & 35 \\
\hline
\end{tabular}

Стоит отметить, что наличие кратных резонансов значительно снижает степень возмущения со стороны больших планет. Энергия астероида, находящегося в резонансе с планетой испытывает только колебания (иногда значительные), не ведущие к прогрессивному изменению размеров орбиты астероида на протяжении всего времени, пока сохраняется резонанс.

При рассмотрении гистограмм распределения численности астероидов группы Амура как функций больших полуосей на три момента времени: 5 января 1800 г., 14 июня 2006 г. и 8 января 2200 г. (рис. 1-3), было замечено, что характер распределения числа астероидов не претерпевает существенных изменений. Это связанно с тем, что резонансные соотношения строятся по среднесуточным движениям планет и астероидов, а, в свою очередь, среднесуточные движения небесного тела являются зависимыми от большой полуоси и рассчитываются по формуле

$$
n=\sqrt{\frac{f(1+m)}{a^{3}}}
$$

где $f$ - квадрат постоянной Гаусса; $m$ - масса тела; $a$-большая полуось орбиты.

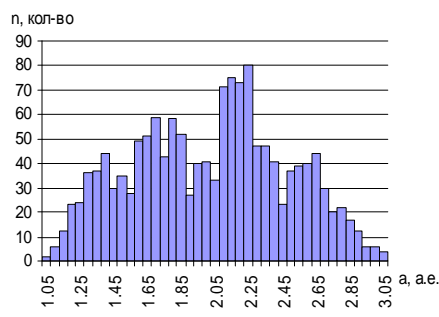

Р и с. 1. Гистограмма распределения численности астероидов группы Амура как функция большой полуоси на 5 января 1800 г.

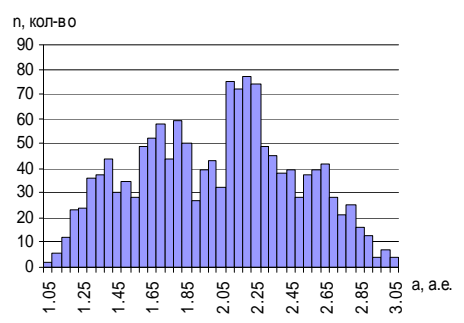

Р и с. 2. Гистограмма распределения численности астероидов группы Амура как функция большой полуоси на 14 июня 2006 г.

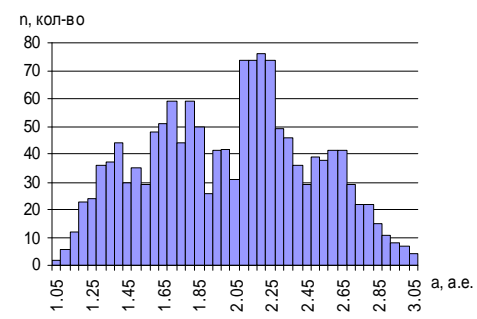

Р и с. 3. Гистограмма распределения численности астероидов группы Амура как функция большой полуоси на 8 января 2200 г.

Благодаря тому, что размеры орбит больших планет практически не изменяются, а по результатам исследования отклонение полученных резонансных отношений от точных соизмеримостей было не существенным на исследуемом промежутке времени, нами была обнаружена устойчивость орбит астероидов, находящихся в резонансе с большими планетами. Из этого 
можно сделать вывод, что наличие кратных резонансов замедляет прогрессивную эволюцию астероидов, уменьшает вероятность столкновения их с большими планетами, и тем самым продлевает срок их существования.

Однако не все астероиды рассмотренной группы Амура находятся в резонансах с большими планетами. Из рассмотренных 1465 астероидов группы Амура у 250 отсутствуют острые соизмеримости периодов с внутренними планетами. Возможно, что эти астероиды имеют более высокую степень вероятности столкновения с большими планетами в сравнении с астероидами, находящимися в резонансе с планетами и к этим объектам должно быть проявлено особое внимание при решении проблемы, связанной с астероидной опасностью.

Исследование резонансов важно как для изучения устойчивости движения отдельных систем, так и Солнечной системы в целом. По-видимому, основной причиной высокой степени устойчивости в динамическом состоянии небесных объектов является сложный вид резонансного взаимодействия тел Солнечной системы. Тела, попавшие в резонанс, могут оставаться захваченными резонансом значительное время. Таким образом, резонансы стабилизируют Солнечную систему на большие периоды времени.

\section{БИБЛИОГРАФИЧЕСКИЙ СПИСОК}

1. Алтынбаев Ф. Х. Исследование устойчивости резонансного характера движения астероидов групп Аполлона, Амура, Атона // Вестн. Сам. гос. техн. ун-та. Сер.: «Физ.-мат. науки», 2004. — № 26. — С. 71-77.

2. Герасимов И. А. Эволюция внешней части кольца астероидов // Автореф. дис. ... докт. физ.-мат. наук. - М., 1992. - $11 \mathrm{c}$.

3. Гребенников Е. А., Рябов Ю. А. Резонансы и малые знаменатели в небесной механике. — М.: Наука, 1971. — $443 \mathrm{c}$.

4. Заусаев А. Ф. Эволюция орбит малых тел Солнечной системы сближающихся с Землёй // Автореф. дис. ... докт. физ.-мат. наук. - М., 1994. — 20 с.

5. Заусаев А. Ф., Заусаев А. А. Каталог орбитальной эволюции короткопериодических комет с 1900 по 2100 гг. М. Машиностроение-1., 2005. - $346 \mathrm{c}$.

6. Заусаев А. Ф., Заусаев А. А., Ольхин А. Г. Применение метода Эверхарта 31 порядка для решения уравнений движения различных небесных объектов // Обозрение прикладной и промышленной математики, 2004. — Т. 11, Вып. 3. - С. 636

7. Everhart E. Implicit single methods for integrating orbits // Celestial Mech., 1974. — No. 10. — P. 35-55.

Работа выполнена при финансовой поддержке Федерального агентства по образованию (проект РНП. 2.1.1.1689).

Поступила 19.09.2006 2. 